University of Wollongong

Research Online

Faculty of Social Sciences - Papers (Archive) Faculty of Arts, Social Sciences \& Humanities

2019

Adiposity and attained height in adolescents: A longitudinal analysis from the LabMed Physical Activity Study

\author{
Rafaela Rosario \\ University of Minho \\ Cesar A. Agostinis-Sobrinho \\ University of Porto \\ Luis Carlos Oliveira Lopes \\ University of Porto, luisl@uow.edu.au \\ Pedro Moreira \\ University of Porto \\ Patricia Padrao \\ University of Porto
}

See next page for additional authors

Follow this and additional works at: https://ro.uow.edu.au/sspapers

Part of the Education Commons, and the Social and Behavioral Sciences Commons

Research Online is the open access institutional repository for the University of Wollongong. For further information contact the UOW Library: research-pubs@uow.edu.au 


\title{
Adiposity and attained height in adolescents: A longitudinal analysis from the LabMed Physical Activity Study
}

\author{
Abstract \\ To investigate the associations between adiposity and attained height over a 2-year period in healthy \\ adolescents. One thousand and seventeen adolescents aged 12-18 years participated in this cohort \\ study; 893 (87.8\%) were reevaluated 1 year later (T2) and 734 (72.2\%) subjects 2 years later (T3). Body fat \\ and anthropometry were measured according to standardized procedures. Socioeconomic status, \\ pubertal stage and lifestyles determinants were gathered and used as confounders. Prospective \\ associations between adiposity and height were examined using generalized linear models. Greater \\ adiposity at $\mathrm{T} 1$ was significantly associated with a lower attained height over time, when adjusting for \\ confounders, which varied between 0.03 and $1 \mathrm{~cm}$ in T2 and 0.1 and $1 \mathrm{~cm}$ in T3. Excess of adiposity in \\ early adolescence may exert an effect on attained height in late adolescence. This study supports future \\ lifestyles intervention studies aiming at preventing overweight and obesity and improving attained height.

\section{Disciplines \\ Education | Social and Behavioral Sciences}

\section{Publication Details} \\ Rosario, R., Agostinis-Sobrinho, C., Lopes, L., Moreira, P., Padrao, P., Oliveira, A., Moreira, C., Povoas, S., \\ Mota, J. \& Santos, R. (2019). Adiposity and attained height in adolescents: A longitudinal analysis from \\ the LabMed Physical Activity Study. Journal of Pediatric Endocrinology and Metabolism, 32 (10), \\ $1131-1137$.

\section{Authors} \\ Rafaela Rosario, Cesar A. Agostinis-Sobrinho, Luis Carlos Oliveira Lopes, Pedro Moreira, Patricia Padrao, \\ Andre Oliveira, Carla Moreira, Susana Povoas, Jorge Mota, and Rute Santos
}


Rafaela Rosário*, Cesar Agostinis-Sobrinho, Luís Lopes, Pedro Moreira, Patrícia Padrão, André Oliveira, Carla Moreira, Susana Póvoas, Jorge Mota and Rute Santos

\section{Adiposity and attained height in adolescents: a longitudinal analysis from the LabMed Physical Activity Study}

https://doi.org/10.1515/jpem-2019-0193

Received April 24, 2019; accepted August 2, 2019; previously published online September 2, 2019

\section{Abstract}

Background: To investigate the associations between adiposity and attained height over a 2-year period in healthy adolescents.

Methods: One thousand and seventeen adolescents aged 12-18 years participated in this cohort study; 893 (87.8\%) were reevaluated 1 year later (T2) and 734 (72.2\%) subjects 2 years later (T3). Body fat and anthropometry were measured according to standardized procedures. Socioeconomic status, pubertal stage and lifestyles determinants were gathered and used as confounders. Prospective associations between adiposity and height were examined using generalized linear models.

Results: Greater adiposity at T1 was significantly associated with a lower attained height over time, when adjusting for confounders, which varied between 0.03 and $1 \mathrm{~cm}$ in $\mathrm{T} 2$ and 0.1 and $1 \mathrm{~cm}$ in $\mathrm{T} 3$.

Conclusions: Excess of adiposity in early adolescence may exert an effect on attained height in late adolescence. This study supports future lifestyles intervention studies aiming at preventing overweight and obesity and improving attained height.

\footnotetext{
*Corresponding author: Rafaela Rosário, School of Nursing, Universidade do Minho, Escola Superior de Enfermagem, $3^{\circ}$ Piso Edif. da Biblioteca Geral (BGUM), Campus de Gualtar, 4710-057 Braga, Portugal; and Health Sciences Research Unit: Nursing (UICISA: E), Nursing School of Coimbra (ESEnfC), Coimbra, Portugal, Phone: (+351) 253601326, Fax: 253 601319,

E-mail: rrosario@ese.uminho.pt

Cesar Agostinis-Sobrinho: Research Centre in Physical Activity, Health and Leisure, Faculty of Sport, University of Porto, Porto, Portugal; Faculty of Health Sciences, Klaipeda University, Klaipeda, Lithuania; and Physical Education, Physiotherapy and Dance, Federal University of the South of Brazil, Porto Alegre, Rio Grande do Sul, Brazil. https://orcid.org/0000-0001-9104-9042 Luís Lopes, André Oliveira, Carla Moreira and Jorge Mota: Research Centre in Physical Activity, Health and Leisure, Faculty of Sport, University of Porto, Porto, Portugal. https://orcid.org/0000-00025827-9281 (A. Oliveira)
}

Keywords: adiposity; adolescent; body height; longitudinal studies; pediatric obesity.

\section{Introduction}

Obesity is a serious health condition for youth and adults and is increasing all worldwide [1]. The etiology of obesity is multifactorial and is beyond the simple equation of energy intake and expenditure [2]. Other factors, such as the pre-natal or neonatal conditions [3, 4], as well as rapid growth [5, 6] might contribute to obesity. On the other hand, children with obesity tend to be taller than their normal-weight peers [7], because they have an acceleration of height velocity and a bone age advancement [8-10]. Additionally, several hormones such as insulin-like growth factor 1 and their binding proteins [11], insulin [12] are elevated in children with obesity and have been suggested as having a role in linear growth. Despite the initial acceleration of bone age and linear growth, children with obesity have an earlier pubertal development [13-15], which might be associated with a loss of growth spurt during adolescence [5] and leading to a tendency of attaining similar height as normal weight adolescents [16, 17].

Pedro Moreira: Research Centre in Physical Activity, Health and Leisure, Faculty of Sport, University of Porto, Porto, Portugal; Faculty of Nutrition and Food Sciences, University of Porto, Porto, Portugal; and Institute of Public Health, University of Porto, Porto, Portugal

Patrícia Padrão: Faculty of Nutrition and Food Sciences, University of Porto, Porto, Portugal; and Institute of Public Health, University of Porto, Porto, Portugal

Susana Póvoas: Research Center in Sports Sciences, Health Sciences and Human Development, CIDESD, University Institute of Maia, ISMAI, Maia, Portugal

Rute Santos: Research Centre in Physical Activity, Health and Leisure, Faculty of Sport, University of Porto, Porto, Portugal; and Early Start and Illawarra Health and Medical Research Institute, University of Wollongong, NSW, Australia 
Most of the studies that reported associations between weight status and height gain in childhood and adolescence used body mass index (BMI) to represent weight status [7, 16-19]. However, there is documented evidence that this index has limitations in the estimation of body fat levels [20]. Additionally, some of these studies had samples of obese subjects [17, 18], are cross-sectional [7] and are from low/middle income countries [19]. The present study further explores the prospective associations between different measures of adiposity besides BMI and attained height during adolescence. Therefore, we investigated the associations between adiposity and attained height over a 2-year period, in healthy adolescents.

\section{Materials and methods}

\section{Study design and participants}

The present study was derived from a school-based prospective research, developed in the North Region of Portugal, named the Longitudinal Analysis of Biomarkers and Environmental Determinants of Physical Activity (LabMed Physical Activity Study). The study aimed to analyze the independent and combined associations of dietary intake and fitness levels on adolescents' cardiometabolic risk over a 3-year period. The full description of the research is reported elsewhere [21, 22].

Baseline (T1) data collection occurred in the fall of 2011 with 1017 adolescents, belonging to five urban schools and aged $14.6( \pm 1.8)$ years. Of those 893 were reevaluated 1 (T2, with $87.8 \%$ of the sample) and 734 subjects 2 years later (T3, with $72.2 \%$ of the sample). A power calculation for the LabMed Study was based on the exposure of combined healthy diet and physical activity pattern with a prevalence of $14 \%$ [23]. A sample of 754 would provide an $80 \%$ power to detect $15 \%$ difference between exposed and unexposed at $5 \%$ significance. Taking into account an expected dropout rate of about $20 \%$ at each timepoint, the sample size was increased to 1086.

\section{Ethical and legal requirements}

The adolescents and their parents or guardians filled in the written informed consent, in agreement with the World Medical Association's Helsinki Declaration for Human Studies [24]. The Portuguese Data Protection Authority (\#1112434/2011), the Portuguese Ministry of Science and Education (0246200001/2011) and the Faculty of Sport, University of Porto, approved the study. We did not have exclusion criteria during the longitudinal data collection, in order to avoid discriminations. Nonetheless, we considered only apparently healthy adolescents in the present analysis, those without any medical diagnoses of physical or mental impairment.

\section{Assessments}

Anthropometrics: Anthropometric assessment followed standardized procedures [25]. Percentage (\%) of body fat was measured with bioimpedance (Tanita Inner Scan BC 532, Tokyo, Japan). Adolescents had an overnight fasting of at least $10 \mathrm{~h}$, stood on the scale with light clothes and with no shoes. Weight was measured with the same digital scale, to the nearest $0.10 \mathrm{~kg}$. A portable stadiometer (Seca 213, Hamburg, Germany) was used for height measurement, with the adolescent in the Frankfort plane to the nearest $0.1 \mathrm{~cm}$ and with no shoes. BMI was computed as weight $(\mathrm{kg}) /$ height $(\mathrm{m})^{2}$.

Waist circumference (WC) was measured with the adolescent in a standing position, to the nearest $0.1 \mathrm{~cm}$. An inextensible tape was used, midway between the lower rib margin and the anterior superior iliac spine, at the end of a normal expiration [25].

A skinfold caliper was used to measure triceps and subscapular skinfolds, with a constant pressure of $10 \mathrm{~g} / \mathrm{mm}^{2}$ (Harpenden Skinfold Caliper Model HSB-BI, West Sussex, UK) according to standard procedures. The participant stood comfortably, with the upper extremities relaxed at the sides of the body. The subscapular was measured in the inferior angle of the scapula and the triceps skinfold on the half distance between the acromion and the olecranon. Both of the measures were performed twice on the non-dominant side of the body and in non-consecutive moments; the mean value was recorded to the nearest $0.1 \mathrm{~mm}$.

\section{Other measurements}

Socioeconomic status was assessed with the family affluence scale, a tool that was developed specifically to measure children and adolescents socioeconomic status in the context of the Health Behaviour in School-aged Children Study [26].

Adolescents self-rated their pubertal development, according to their secondary sex characteristics, breasts in females, genitals in males and pubic hair in both sexes. The stages ranged from stage I (prepubertal) to V (postpubertal) [27].

Adherence to the Mediterranean Diet Quality Index for children and adolescents (Kidmed) was used to assess the degree of adherence to a Mediterranean diet [28]. Participants filled the 16-questions index, which sustain the principles of Mediterranean dietary patterns as well as those that undermine it, according to standardize criteria [28]. The final sum of the index ranged from 0 to 12 and the participants were classified into three levels: (i) $\geq 8$, optimal Mediterranean diet; (ii) 4-7, improvement needed to adjust intake to Mediterranean patterns; (iii) $\leq 3$, very low diet quality.

Cardiorespiratory fitness was measured with the $20-\mathrm{m}$ Shuttle Run Test (20 m SRT) and maximal oxygen consumption $\left(\mathrm{VO}_{2 \max }\right)$ was calculated [29] at T1 and T3. A detailed description of this test protocol can be seen elsewhere [30].

\section{Statistical analysis}

Descriptive statistics are presented as means and standard deviations (SDs) and percentages according to the type of variables. Differences between and within subjects over time were tested using repeated measures analysis of variance (ANOVA) for normally distributed variables, chi-squared for percentages and the Friedman test for ordinal and non-normally distributed variables.

Associations between adiposity, i.e. \% of body fat, BMI, WC triceps and subscapular skinfolds at $\mathrm{T} 1$ (predictors) and attained height at T1, T2 and T3 (dependent variables) were performed using generalized linear models. The models were further adjusted for baseline 
measures of age, socioeconomic status, pubertal stage, cardiorespiratory fitness, adherence to a Mediterranean diet categories and height. As there was significant interaction between sex and anthropometry, the results were further stratified by sex. Drop out analysis showed that adolescents lost to follow-up are not significantly different from those that were retained throughout the study.

The data analysis was performed using SPSS, version 23.0 (SPSS Inc., Chicago, IL, USA), with a 0.05 level of significance considered.

\section{Results}

Table 1 reports the characteristics of the sample at T1, T2 and T3. At baseline, 1017 adolescents (53.4\% boys) participated in the study; at T2 893 adolescents ( $53.1 \%$ boys); and at T3 734 adolescents (52.5\% boys). There were significant differences regarding pubertal development (breasts/ genitals) in girls and boys, at baseline. Of the boys $45.6 \%$ and $51 \%$ of girls were in Tanner stage 4 for breasts and genitals, respectively, whereas $52.9 \%$ of boys and $49.7 \%$ of girls were in Tanner stage 4 for pubic hair. No differences were found in $\mathrm{T} 2$ and $\mathrm{T} 3$.

Anthropometric variables were significantly different over time within subjects and between sexes. Skinfolds increased over time and were significantly higher in girls when compared to boys, whereas height and weight increased over time and were significantly higher in boys. The $\%$ of body fat was significantly higher in girls in each time of evaluation (T1, T2 and T3; please see Table 1).

Looking at cross-sectional data (T1) from Table 2, in the full adjusted model, boys with higher measures of adiposity ( $\%$ body fat, BMI, WC and skinfolds) had a significantly higher height between $0.2 \mathrm{~cm}$ in triceps skinfolds and $2 \mathrm{~cm}$ associated with a higher 10\% body fat. In girls there were associations between both WC and triceps and attained height. An increase of $1 \mathrm{~cm}$ in both measures was significantly associated with $0.1 \mathrm{~cm}$ higher height.

In the full-adjusted model, a 10\% higher body fat at T1 was significantly associated with a lower height of $1 \mathrm{~cm}$ both at T2 $(1 \mathrm{~cm}$ in boys and $0.4 \mathrm{~cm}$ in girls $)$ and T3 $(1 \mathrm{~cm}$ in boys and girls). Conversely, a $1 \mathrm{~kg} / \mathrm{m}^{2}$ higher in BMI at baseline was significantly associated with a lower height of $0.1 \mathrm{~cm}$ at T2 $(0.2 \mathrm{~cm}$ in boys and $0.05 \mathrm{~cm}$ in girls $)$ and $0.2 \mathrm{~cm} \mathrm{T3}(0.2 \mathrm{~cm}$ in boys and $0.1 \mathrm{~cm}$ in girls). Regarding $\mathrm{WC}$, an increase of $1 \mathrm{~cm}$ at baseline was significantly associated with a lower attained height, only in boys, of $0.05 \mathrm{~cm}$ at T2 and $0.1 \mathrm{~cm}$ at T3. Similar results were found for skinfolds thickness; in boys, an increase of triceps skinfolds was associated with a significantly lower height of $0.04 \mathrm{~cm}$ at T2. An increase in subscapular skinfolds at baseline was associated with a significantly lower attained height of $0.04 \mathrm{~cm}$ in T2 $(0.1 \mathrm{~cm}$ in boys $)$ and $0.1 \mathrm{~cm}$ in T3 $(0.1 \mathrm{~cm}$ both in boys and girls) (Table 2$)$.

\section{Discussion}

In this prospective study, we documented that higher $\%$ body fat, BMI, WC, triceps and subscapular skinfolds thickness were associated with a decrease in attained height during adolescence, after adjusting the analysis for socio-economic status, pubertal stage, adherence to a Mediterranean diet, cardiorespiratory fitness, age and baseline measure of height. This is particularly important because anthropometry is considered a proxy-measure of biological welfare [31] and height might be a variable of interest when analyzing obesity status in adolescents. Notwithstanding, height might be to some extent genetically determined [32], attained adult height is a marker of early exposures affecting growth [33], which may include adiposity.

We know that excess in adiposity is a result of several determinants of lifestyles, such as unhealthy eating patterns, sedentary behavior and lack of physical activity [34]. In our cross-sectional data, there are positive associations between adiposity and height. It is possible that energy intake is enough not only to achieve rapid linear growth, but also to store the excess as subcutaneous fat. We are aware that, besides height and adiposity, other associations might exist between lifestyles and height, and future studies should consider them. In addition, we observe a change in the association of $\%$ body fat and triceps skinfolds with height from negative in unadjusted, to positive in the full adjusted model. There is a strong impact of the adjustment to cardiorespiratory fitness itself. This is in accordance with previous studies where fitness performance is positively associated with bone mass [35] and mediated by lean mass [36].

In $\mathrm{T} 2$ and $\mathrm{T} 3$, there is a change in the direction of the association between BMI, WC and height from positive to negative, while in $\mathrm{T} 1$ the association remained positive. In the present report young adolescents with higher adiposity, including BMI and WC, are taller, but in late adolescence (in T2 and T3), they have a lower attained height. In agreement with our findings, it has been reported that children with obesity have a higher growth velocity during childhood [16] and tend to have bone ages older than their chronological ages $[8,9]$, leading to a relatively higher height before and during early puberty. Furthermore, children with obesity have a reduced production of growth hormone, whereas the synthesis of insulin-like 


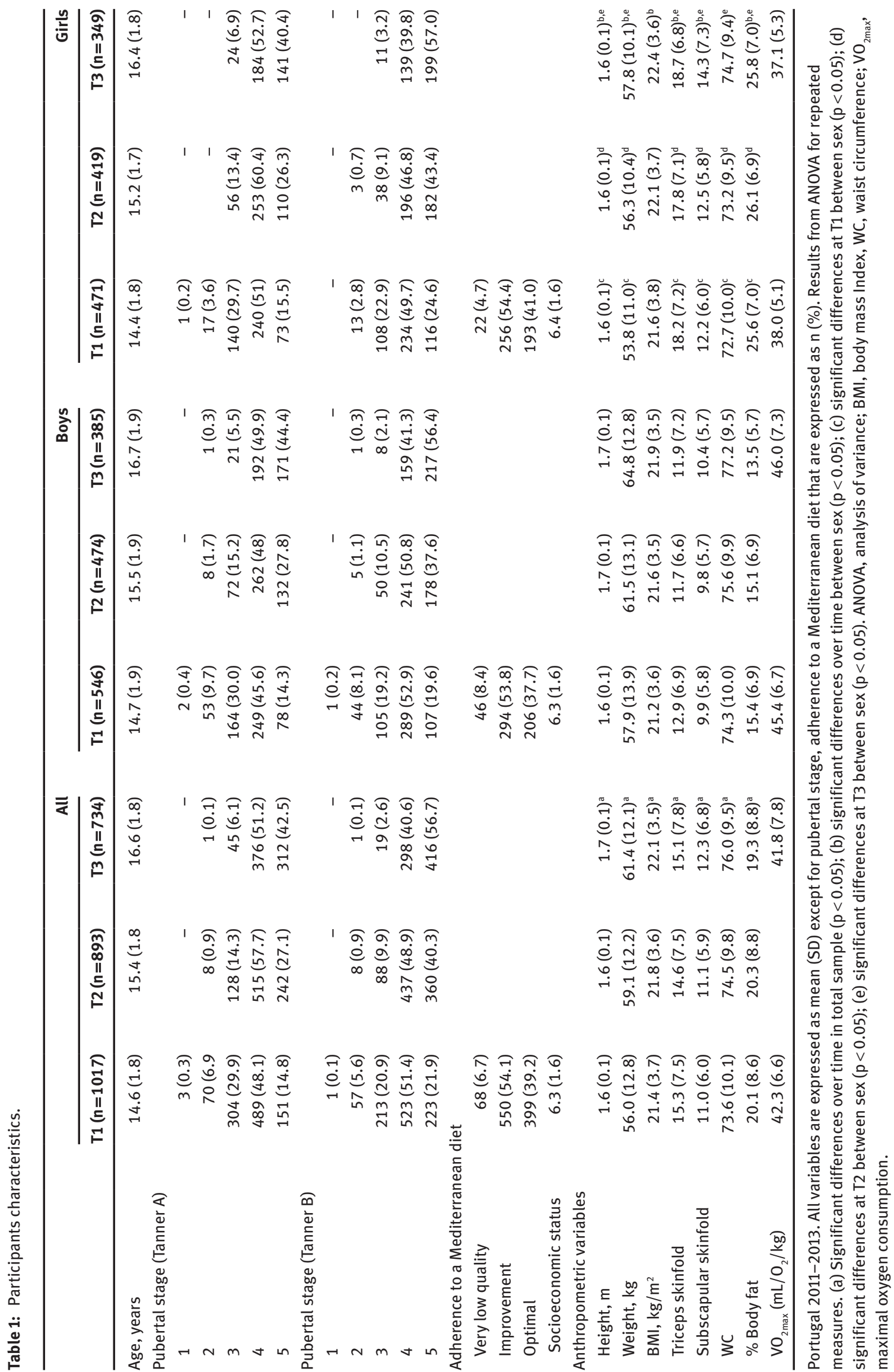




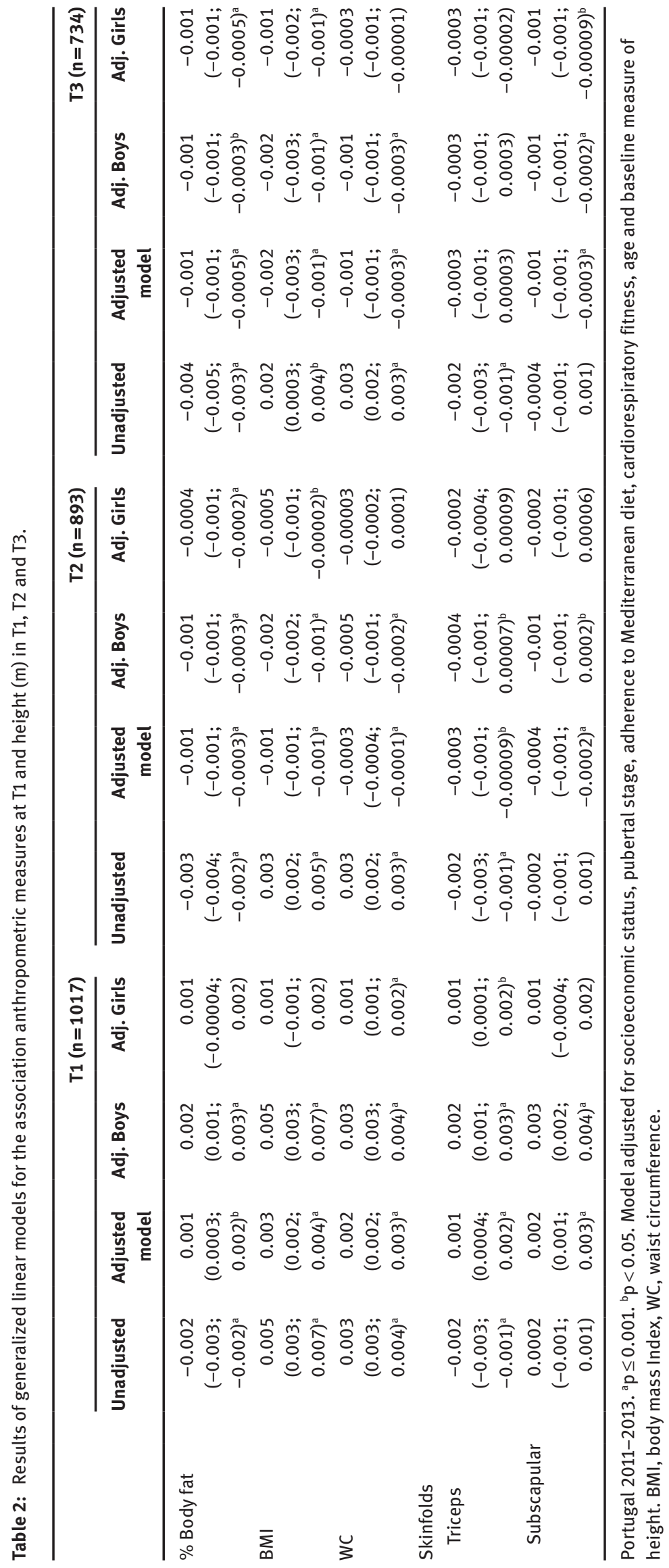


growth factor 1 is normal $[37,38]$. Despite the abnormality in this axis, during childhood, subjects with obesity have a normal or an accelerated growth, possibly explained by the availability of insulin, insulin-like growth factors and their binding proteins [10]. Moreover, rapid growth and rapid increase in BMI in childhood predict earlier initiation and faster tempo for pubertal trajectory classes [39], which have been associated with short adult stature [16, 40]. During adolescence, subjects with obesity experience a lower growth spurt than do thinner adolescents, having a lower attained height in late adolescence and adulthood $[9,16,17]$. In the current report, and in agreement with previous studies [7], the observed associations were independent of sexual maturation.

This study has several strengths that should be emphasized. First, its longitudinal design allowed an analysis of the associations between adiposity and height over time. Second, we included different measures of adiposity ( $\%$ body fat, BMI, WC and skinfolds), emphasizing their relevance in growth and height attainment over time in adolescents. Third, the adjustment for major potential confounders including cardiorespiratory fitness, socioeconomic status, age, pubertal stage, adherence to a Mediterranean diet, which can account for part of the determinants of attained height. To the best of our knowledge, this is the first study that accounted for all of these variables in adolescence, including a valid and accurate cardiorespiratory fitness field test [30], which offers evidence about the independent impact of adiposity on attained height.

The present study also has limitations. We gathered adherence to a Mediterranean diet through the KidMed questionnaire. Although it is the most widely used instrument to score a Mediterranean diet in children and adolescents, further validations would be interesting [41]. While we adjusted for multiple potential confounders, others might exist, such as income and parents' height. Nonetheless, we used a tool to characterize the sociodemographic profile developed for adolescents and schoolbased studies [26].

Despite the increasing trends of overweight and obesity all over the world [1], Western populations who are taller still have high obesity prevalence. Height is a simple indicator of health and welfare [31] and to achieve the maximum of its potential, seems to be important in preventing adiposity during adolescence.

Acknowledgments: This study was supported by the Research Centre on Physical Activity Health and Leisure (CIAFEL) of the Faculty of Sport, University of Porto and by FCT grant BD88984/2012 (J. Oliveira-Santos); The Research Centre on Physical Activity Health and Leisure
(CIAFEL) is supported by UID/DTP/00617/2013 (FCT); the author C. Agostinis-Sobrinho was given Doctoral scholarship from the Brazilian government by CAPES (Coordination of Improvement of Higher Education Personnel) (Proc: 9588-13-2). R. Santos has a Discovery Early Career Research Award from the Australian Research Council (DE150101921). The authors gratefully acknowledged the participation of all adolescents and their parents, teachers and schools of the LabMed Study. They also acknowledge the cooperation of volunteer's subjects and the Research Centre in Physical Activity, Health and Leisure (University of Porto) for the sponsoring the LabMed Study. The Research Centre on Physical Activity Health and Leisure is supported by FCT/UID/00617/2019.

Author contributions: All the authors have accepted responsibility for the entire content of this submitted manuscript and approved submission.

Research funding: None declared.

Employment or leadership: None declared.

Honorarium: None declared.

Competing interests: The funding organization(s) played no role in the study design; in the collection, analysis, and interpretation of data; in the writing of the report; or in the decision to submit the report for publication.

\section{References}

1. Swinburn BA, Kraak VI, Allender S, Atkins VJ, Baker PI, et al. The Global Syndemic of Obesity, Undernutrition, and Climate Change: The Lancet Commission report. Lancet 2019;393:791-846.

2. Pereira-Fernandes A, Dirinck E, Dirtu AC, Malarvannan G, Covaci A, et al. Expression of obesity markers and persistent organic pollutants levels in adipose tissue of obese patients: reinforcing the obesogen hypothesis? PLoS One 2014;9:e84816.

3. Jornayvaz FR, Vollenweider P, Bochud M, Mooser V, Waeber G, et al. Low birth weight leads to obesity, diabetes and increased leptin levels in adults: the CoLaus study. Cardiovasc Diabetol 2016;15:73.

4. Ramirez-Velez R, Correa-Bautista JE, Villa-Gonzalez E, MartinezTorres J, Hackney AC, et al. Effects of preterm birth and fetal growth retardation on life-course cardiovascular risk factors among schoolchildren from Colombia: the FUPRECOL study. Early Hum Dev 2017;106-107:53-8.

5. Stovitz SD, Demerath EW, Hannan PJ, Lytle LA, Himes JH. Growing into obesity: patterns of height growth in those who become normal weight, overweight, or obese as young adults. Am J Hum Biol 2011;23:635-41.

6. Freedman DS, Khan LK, Mei Z, Dietz WH, Srinivasan SR, et al. Relation of childhood height to obesity among adults: the Bogalusa Heart Study. Pediatrics 2002;109:E23.

7. Freedman DS, Thornton JC, Mei Z, Wang J, Dietz WH, et al. Height and adiposity among children. Obes Res 2004;12:846-53. 
8. Sopher AB, Jean AM, Zwany SK, Winston DM, Pomeranz CB, et al. Bone age advancement in prepubertal children with obesity and premature adrenarche: possible potentiating factors. Obesity (Silver Spring) 2011;19:1259-64.

9. Johnson W, Stovitz SD, Choh AC, Czerwinski SA, Towne B, et al. Patterns of linear growth and skeletal maturation from birth to 18 years of age in overweight young adults. Int J Obes (Lond) 2012;36:535-41.

10. Shalitin S, Kiess W. Putative effects of obesity on linear growth and puberty. Horm Res Paediatr 2017;88:101-10.

11. Attia N, Tamborlane WV, Heptulla R, Maggs D, Grozman A, et al. The metabolic syndrome and insulin-like growth factor I regulation in adolescent obesity. J Clin Endocrinol Metab 1998;83:1467-71.

12. Srinivasan SR, Myers L, Berenson GS. Temporal association between obesity and hyperinsulinemia in children, adolescents, and young adults: the Bogalusa Heart Study. Metabolism 1999;48:928-34.

13. Davison KK, Susman EJ, Birch LL. Percent body fat at age 5 predicts earlier pubertal development among girls at age 9 . Pediatrics 2003;111(4 Pt 1):815-21.

14. Kaplowitz PB, Slora EJ, Wasserman RC, Pedlow SE, Herman-Giddens ME. Earlier onset of puberty in girls: relation to increased body mass index and race. Pediatrics 2001;108:347-53.

15. Lee JM, Wasserman R, Kaciroti N, Gebremariam A, Steffes J, et al. Timing of puberty in overweight versus obese boys. Pediatrics 2016;137:e20150164.

16. He Q, Karlberg J. BMI in childhood and its association with height gain, timing of puberty, and final height. Pediatr Res 2001;49:244-51.

17. Kleber M, Schwarz A, Reinehr T. Obesity in children and adolescents: relationship to growth, pubarche, menarche, and voice break. J Pediatr Endocrinol Metab 2011;24:125-30.

18. Vignolo M, Naselli A, Di Battista E, Mostert M, Aicardi G. Growth and development in simple obesity. Eur J Pediatr 1988;147:242-4.

19. Stein AD, Lundeen EA, Martorell R, Suchdev PS, Mehta NK, et al. Pubertal development and prepubertal height and weight jointly predict young adult height and body mass index in a prospective study in South Africa. J Nutr 2016;146:1394-401.

20. Peterson CM, Su H, Thomas DM, Heo M, Golnabi AH, et al. Triponderal mass index vs body mass index in estimating body fat during adolescence. JAMA Pediatr 2017;171:629-36.

21. Agostinis-Sobrinho C, Santos R, Moreira C, Abreu S, Lopes L, et al. Association between serum adiponectin levels and muscular fitness in Portuguese adolescents: LabMed Physical Activity Study. Nutr Metab Cardiovasc Dis 2016;26:517-24.

22. Almeida-de-Souza J, Santos R, Lopes L, Abreu S, Moreira C, et al. Associations between fruit and vegetable variety and low-grade inflammation in Portuguese adolescents from LabMed Physical Activity Study. Eur J Nutr 2018;57:2055-68.

23. Huh J, Riggs NR, Spruijt-Metz D, Chou CP, Huang Z, et al. Identifying patterns of eating and physical activity in children: a latent class analysis of obesity risk. Obesity (Silver Spring) 2011;19:652-8.

24. World Medical Association. World Medical Association handbook of declarations. Ferney Voltaire, France: World Medical Association, 1989.
25. Lohmann T, Roche A, Martorell R. Anthropometric standardization reference manual. Champaign, IL: Human Kinetics Books, 1988.

26. Currie C, Molcho M, Boyce W, Holstein B, Torsheim T, et al. Researching health inequalities in adolescents: the development of the Health Behaviour in School-Aged Children (HBSC) family affluence scale. Soc Sci Med 2008;66:1429-36.

27. Tanner JM, Whitehouse RH. Clinical longitudinal standards for height, weight, height velocity, weight velocity, and stages of puberty. Arch Dis Child 1976;51:170-9.

28. Serra-Majem L, Ribas L, Ngo J, Ortega RM, García A, et al. Food, youth and the mediterranean diet in Spain. Development of KIDMED, Mediterranean Diet Quality Index in children and adolescents. Public Health Nutrition 2004;7:931-5.

29. Leger LA, Mercier D, Gadoury C, Lambert J. The multistage 20 metre Shuttle Run Test for aerobic fitness. J Sports Sci 1988;6:93-101.

30. Ruiz JR, Castro-Pinero J, Espana-Romero V, Artero EG, Ortega $\mathrm{FB}$, et al. Field-based fitness assessment in young people: the ALPHA health-related fitness test battery for children and adolescents. Br J Sports Med 2011;45:518-24.

31. Komlos J, Baur M. From the tallest to (one of) the fattest: the enigmatic fate of the American population in the 20th century. Econ Hum Biol 2004;2:57-74.

32. Marouli E, Graff M, Medina-Gomez C, Lo KS, Wood AR, et al. Rare and low-frequency coding variants alter human adult height. Nature 2017;542:186-90.

33. Silventoinen K. Determinants of variation in adult body height. J Biosoc Sci 2003;35:263-85.

34. Swinburn BA, Sacks G, Hall KD, McPherson K, Finegood DT, et al. The global obesity pandemic: shaped by global drivers and local environments. Lancet 2011;378:804-14.

35. Gracia-Marco L, Vicente-Rodriguez G, Casajus JA, Molnar D, Castillo MJ, et al. Effect of fitness and physical activity on bone mass in adolescents: the HELENA Study. Eur J Appl Physiol 2011;111:2671-80.

36. Ubago-Guisado E, Vlachopoulos D, Ferreira de Moraes AC, Torres-Costoso A, Wilkinson K, et al. Lean mass explains the association between muscular fitness and bone outcomes in 13-year-old boys. Acta Paediatr 2017;106:1658-65.

37. Scacchi M, Pincelli Al, Cavagnini F. Growth hormone in obesity. Int J Obes Relat Metab Disord 1999;23:260-71.

38. Iranmanesh A, Lizarralde G, Veldhuis JD. Age and relative adiposity are specific negative determinants of the frequency and amplitude of growth hormone $(\mathrm{GH})$ secretory bursts and the half-life of endogenous GH in healthy men. J Clin Endocrinol Metab 1991;73:1081-8.

39. Lundeen E, Norris S, Martorell R, Suchdev P, Mehta N, et al. Early life growth predicts pubertal development in South African adolescents. J Nutr 2016;146:622-9.

40. Biro FM, McMahon RP, Striegel-Moore R, Crawford PB, Obarzanek $E$, et al. Impact of timing of pubertal maturation on growth in black and white female adolescents: the National Heart, Lung, and Blood Institute Growth and Health Study. J Pediatr 2001;138:636-43.

41. Della Corte C, Mosca A, Vania A, Alterio A, lasevoli S, et al. Good adherence to the Mediterranean diet reduces the risk for NASH and diabetes in pediatric patients with obesity: the results of an Italian Study. Nutrition 2017;39-40:8-14. 